\title{
Gestasyonel Yaşları 32 Haftadan Küçük Doğan Prematürelerde Transportun Mortalite ve Morbiditeye Etkisi
}

\section{The Effect of Transport on Mortality and Morbidity in Preterm Infants Less than 32 Weeks of Gestation}

\author{
Selahattin Katar, Doğan Yıldız, Abdülkadir Turgut*, Mustafa Taşkesen**, Günay Saka*** \\ Veni Vidi Özel Hastanesi, Yenidoğan Yoğun Bakım Ünitesi, Diyarbakır, Türkiye \\ *Dicle Üniversitesi, Kadın Hastalıkları ve Doğum Anabilim Dalı, Diyarbakır, Türkiye \\ **Dicle Üniversitesi Çocuk Sağlığı ve Hastalıkları Anabilim Dalı, Diyarbakır, Türkiye

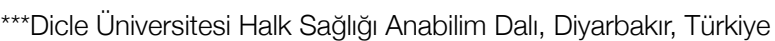

Anahtar kelimeler

Prematüre, transport, mortalite ve morbidite

Key words

Premature, transport, mortality and morbidity

Geliş Tarihi/Received : 22.04.2013

Kabul Tarihi/Accepted : 08.11.2013

DOI:10.4274/jcp.70288

Yazışma Adresi/Address for Correspondence: Dr. Selahattin Katar, Veni Vidi Özel Hastanesi, Yenidoğan Yoğun Bakım Ünitesi, Diyarbakır, Türkiye

Tel.: +90 4122292005

E-posta: katar.selahattin27@gmail.com

(C) Güncel Pediatri Dergisi, Galenos Yayınevi tarafından basılmışıır. (c) The Journal of Current Pediatrics, published by Galenos Publishing.

\section{Özet}

Giriş: Bu çalışmada amaç, hastanemizde doğan ve gestasyonel yaşları 32 haftadan küçük prematüre bebeklerle dış merkezlerde doğduktan sonra hastanemize transfer edilen gestasyonel yaşları 32 haftadan küçük prematüre bebeklerin mortalite ve morbidite sonuçlarını karşılaştırmaktır.

Gereç ve Yöntem: Hastanemizde doğan gestasyonel yaşları 32 haftadan küçük 40 hasta (Grup 1) ile aynı süre içerisinde dış merkezlerde doğup hastanemize transfer edilen ve gestasyonel yaşları 32 haftadan küçük 108 prematüre hasta (Grup 2) araştırmaya alındı. İki grup arasında mortalite ve morbidite (intraventriküler kanama (IVK), prematüre retinopatisi (ROP), respiratuvar distres sendromu (RDS), nekrotizan enterokolit (NEK) ve bronkopulmoner displazi (BPD)) açısından karşılaştırma yapıldı.

Bulgular: Her iki grupta demografik özellikler, cinsiyet, vücut ağırlığg ve gestasyonel yaş verileri benzerdi $(\mathrm{p}>0,05)$. Grup 2'de normal vaginal yol ile doğum daha fazlaydı $(\mathrm{p}<0,001)$

Grup 2'deki hastaların başvuru anında \%90'nında hipotermi, \%2,7'sinde ise hipoglisemi saptandı. Grup 2'deki hastaların mortalitesi Grup 1'e göre daha yüksek, ancak istatistiksel olarak anlamlı değildi ( $\mathrm{p}>0$,05). İVK, ROP, RDS, NEK ve BPD Grup 2'de daha yüksek oranda görülmesine rağmen, iki grup arasındaki karşılaştırmada istatistiksel olarak anlamlı farklılık saptanmadı ( $>>0,05)$.

Sonuç: Sonuç olarak, doğduktan sonra prematürelerin transfer edilmesi mortalite ve morbiditeyi olumsuz yönde etkilemektedir. Bu nedenle acil durumlar dişında en iyi transportun intrauterin transport olduğu, özellikle ileri derecede prematüre doğan hastaların en üst düzeyde imkanları olan merkezlerde tedavi edilmeleri gerektiği unutulmamalıdır. (Güncel Pediatri 2014;1:16-9)

\footnotetext{
Abstract

Introduction: The aim of this study was to compare mortality and morbidity rates of premature infants with gestational age of less than 32 weeks who were born in our hospital and those who were transported to our hospital after birth from other centers.

Materials and Methods: Patients were divided into two groups; Group 1 included 40 patients who were born before gestational age of 32 weeks in our hospital, and Group 2 included 108 premature patients who were born before gestational age of 32 weeks in other centers and later transferred to our hospital. Morbidity and
} 
mortality rates were compared between the two groups (intraventricular hemorrhage (IVH), retinopathy of prematurity (ROP), respiratory distress syndrome (RDS), necrotizing enterocolitis (NEC), and bronchopulmonary dysplasia (BPD)).

Results: Demographic characteristics, gender, body weight, and gestational age were similar in both groups $(\mathrm{p}>0.05)$. The rate of normal vaginal delivery births was higher in Group $2(\mathrm{p}<0.001)$. On admission, hypothermia was detected in $90 \%$ of the patients and hypoglycemia was found in $2.7 \%$ of patients in Group 2. Mortality was higher in Group 2 than in Group 1, however the difference was not significant $(\mathrm{p}>0.05)$. Although higher rates of IVH, ROP, RDS, NEC, and BPD were found in Group 2, there was no statistically significant difference between the two groups ( $>0.05)$.

Conclusions: Being transferred after birth has a negative effect on morbidity and mortality in premature infants. Thus, the best transport method is intrauterine transport except in state of an emergency, especially for infants with severe prematurity; these patients should be treated in centers with facilities of the highest level. (The Journal of Current Pediatrics 2014;1:16-9)

\section{Giriş}

Yenidoğan transportu perinatal sağlık sisteminin en önemli konularından biridir (1). Tıptaki teknolojik gelişmelere rağmen, en iyi transport anne karnındayken yapılandır (2,3). Ancak önceden öngörülmeyen ve acil nedenlerden dolayı, birçok hasta doğduktan sonra başka bir merkeze transfer edilmek zorunda kalıyor. Transportun yenidoğan hastalarda mortalite ve morbiditeyi arttırdığı çalışmalarda bildirilmiştir (3-7). Özellikle prematürelerde transport, mortalite ve mobidetenin daha çok artmasına neden olabilmektedir. $\mathrm{Bu}$ çalışmada amaç, aynı süre içinde hastanemizde doğan ve diş merkezlerde doğduktan sonra hastanemize transfer edilen gestasyonel yaşları 32 haftadan küçük olan prematüre hastaların mortalite ve morbidite sonuçlarını karşılaştırmaktır.

\section{Gereç ve Yöntemler}

Bu çalışmada, 1 Ağustos 2010-31 Aralık 2011 tarihleri arasında hastanemizde doğan gestasyonel yaşları 32 haftadan küçük 40 hasta ile bu süre içerisinde diş merkezlerde doğup hastanemize transfer edilen ve gestasyonel yaşları 32 haftadan küçük 108 hastanın dosyaları retrospektif olarak incelendi. Hastanemizde doğanlar Grup 1, dış merkezlerde doğduktan sonra hastanemize transfer edilen hastalar Grup 2 olarak sınıflandı. İki gruptaki hastaların cinsiyeti, vücut ağırlığı, gestasyon yaşı, doğum şekli, mortalite oranı, IVH, ROP, RDS, BPD, NEK sıklığı bakımından karşılaştırma yapıldı. IVH Papile evrelendirmesine, ROP Uluslar arası retinopati kriterlerine, RDS kinik ve radyolojik bulgulara, BPD Amerikan sağlık enstitüleri sinıflandırmasına ve NEK Modifiye Bell evrelendirmesine göre tanımlandı. Hastalar doğduktan sonra 1 ile 6 saat arasında ve ikisi hava ambulansı, diğerleri ise karayolu ambulansı ile bir sağlık personeli refakatinde sevk edilmişlerdi. Her transfer öncesinde yenidoğan yoğun bakım ünitemize haber verilerek sevk yapılmıştı. Yenidoğan yoğun bakım ünitesi doğumhane ile aynı katta ve ameliyathanenin iki kat üstünde yer almaktadır. Doğumlardan önce radyant 1sıtıcı çalışır durumda bekletilir. Hastanemizde doğan riskli term ve preterm bebekler, çocuk sağlığı ve hastalıkları uzmanı ve yenidoğan hemşiresi tarafından gerekli ilk müdahaleler yapıldıktan sonra önceden çalışır vaziyette bekletilen transport kuvözle yenidoğan yoğun bakım ünitesine alınır. Çok düşük doğum ağırlıklı bebekler naylon streçlere sarılarak transport edilir. Hasta yenidoğan yoğun bakım ünitesine alınır alınmaz vücut 1sısı bakılır. Başvuruda vücut sıcaklığının $36{ }^{\circ} \mathrm{C}$ 'nin altında olması hipotermi, kan şekerinin $45 \mathrm{mg} / \mathrm{dl}$ 'nin altında olması hipoglisemi, oksijen saturasyonunun \%86'nın altında olması hipoksi olarak değerlendirildi.

\section{Bulgular}

Çalışmaya alınan, gestasyonel yaşı 32 haftadan küçük olan toplam 148 prematüre hastadan 40'1 hastanemizde doğdu, 108 hasta ise dış merkezlerde doğduktan sonra hastanemize transfer edildi. Her iki grupta demografik özellikler, doğum şekli dişında benzer idi. Grup 2'de normal vaginal yol ile doğum daha fazlaydı. Cinsiyet, vücut ağırlı̆̆ı, gestasyonel yaş açısından iki grup arasında anlamlı farklılık yoktu.

Grup 1'deki hastaların \%82,5'ine, Grup 2'deki hastaların ise \%27,7'sine doğumdan önce steriod yapıldığı öğrenildi $(\mathrm{p}<0,05)$. Grup 1'deki hastaların $\% 27,5$ 'i, Grup 2'deki hastaların ise \%12'si çoğul gebelik idi $(\mathrm{p}<0,05)$. Grup 2'deki hastaların başvuru anında \%90'nında hipotermi, \%2,7'sinde hipoglisemi saptand1. Grup 1'deki hastalarda başlangıçta hipotermi ve hipoglisemi saptanmadi. Grup 2'deki hastaların tümünde hipoksiye ait bulgular mevcuttu.

Grup 2'deki hastaların mortalitesi (\%12) Grup 1 'e göre $(\% 7,5)$ daha yüksek idi. Morbidite açısından 
IVK, ROP, RDS, NEK, BPD Grup 2'de daha yüksek oranda saptandı. Hastaların klinikte yattığı gün sayısı bakımından anlamlı farklılık saptanmadı ( $=0,918)$. Hastaların demografik özellikleri, mortalite ve morbidite oranları Tablo 1'de verilmiştir.

\section{Tartışma}

Yapılan çalışmalarda transportun hem term hem de preterm hastalarda mortaliteyi arttırdığ bildirilmektedir. Gülez ve ark.'nın (4) yaptıkları çalışmada, dış merkezlerde doğup, hastanelerine sevk edilen 571 olgu içinde term hastaların $\% 16,1$ 'i, preterm hastaların (1500-2350 g) ise \%36,7'sinin kaybedildiğini bildirmişlerdir. Hastaneye başvurduktan sonraki 24 saat içinde term hastaların $\% 3,8$ 'i, preterm hastaların ise $\% 9,2$ 'sinin kaybedildiğini belirtmişlerdir. Uslu ve ark.'nın (5) gestasyonel yaş ayırımı yapmadan ancak transport şartları düzeltilmiş grup $(2558 \pm 873 \mathrm{~g})$ ile transport şartları uygun olmayan gruptaki $(2519 \pm 899$ g) hastaların mortalite oranını sırasıyla $\% 18,4$ ve 14,1 olarak bildirmişlerdir. Çalışmamızda transfer edilen grupta mortalite oran $1 \% 12$, transfer edilmeyen grupta ise \% 7,5 olarak saptand. Transfer edilen hastalarda kaybedilenlerin \%38,4’ü ilk 24 saat içinde kaybedildi. İstatistiksel olarak anlamlı farklılık olmamasına rağmen, transfer edilen grupta mortalite oranı diğer gruptan yüksek olarak saptand.

Grup 2'deki hastaların mortalitesi (\%12) Grup 1'e göre $(\% 7,5)$ daha yüksek idi. Morbidite açısından IVK, ROP, RDS, NEK, BPD Grup 2'de daha yüksek oranda saptandı. Ancak yapılan karşılaştırmada istatistiksel anlamlı farklılık saptanamadı, bunun hasta sayısının az olmasına bağlı olabileceği düşünüldü.

Ayrıca birçok çalışmada transportun morbiditeyi arttırdığ1 gösterilmiştir. Bir çalışmada transportun prematürelerde periventriküler lökomalazi/IVK için önemli bir risk faktörü olduğu bildirilmiştir (6). Başka çalışmalarda transfer edilen prematüre hastalar ile transfer edilmeyen gruba göre IVK görülmesi açısından önemli bir fark olduğunu bildirmişlerdir $(4,7)$. Yine bir çalışmada vücut ağırlıkları 1500 gramın altında olan ve transport edilen hastalarda \%27,4, transport edilmemiş olanlarda ise \% 13,4 oranında İVK görüldüğü bildirilmiştir (8). Çalışmamızda transport edilen gruptaki hastaların \%25,9'unda, transport edilmeyen grupta ise \% 12,5 oranında IVK görüldü $(\mathrm{p}=0,08)$.

Bir çalışmada yenidoğanlarda transportun şiddetli ROP açısından önemli bir risk faktörü olduğu bildirilmiştir (9). Çalışmamızda transport edilen gruptaki hastaların \%20,4'ünde, transport edilmeyen gruptaki hastalarda ise $\% 10$ oranında ROP görüldü $(\mathrm{p}=0,141)$.

Tablo 1. Hastaların demografik, mortalite ve erken morbidite özellikleri

\begin{tabular}{|c|c|c|c|}
\hline Hastaların özellikleri & 1. Grup & 2. Grup & $\mathrm{p}$ \\
\hline Say1 & 40 & 108 & \\
\hline Cinsiyet $(\mathrm{K} / \mathrm{E})$ & $19 / 21$ & $57 / 51$ & 0,40 \\
\hline Vücut ağırlı̆̆ & $1534 \pm 31(870-1940)$ & $1453 \pm 438(480-2150)$ & 0,29 \\
\hline Gebelik haftası & $30,0 \pm 2,0$ & $29,3 \pm 2,5$ & 0,11 \\
\hline Doğum şekli (normal vaginal yol/sezeryan) & $3 / 37$ & $30 / 78$ & 0,001 \\
\hline Çoğul gebelik & $\% 27,5$ & $\% 12$ & 0,023 \\
\hline Antenatal steroid & $\% 82,5$ & $\% 27,7$ & 0,000 \\
\hline Hipotermi & $\% 0$ & $\% 90$ & 0,000 \\
\hline Hipoglisemi & $\% 0$ & $\% 2,7$ & 0,563 \\
\hline Hipoksi & $\% 0$ & $\% 100$ & 0,000 \\
\hline Mortalite & $\% 7,5(n=3)$ & $\% 12(n=13)$ & 0,55 \\
\hline \multicolumn{4}{|l|}{ Morbidite } \\
\hline İVK & $\% 12,5(\mathrm{n}=5)$ & $\% 25,9(\mathrm{n}=28)$ & 0,08 \\
\hline ROP & $\% 10(n=4)$ & $\% 20,4(n=22)$ & 0,14 \\
\hline RDS & $\% 57,5(n=23)$ & $\% 65,7(n=71)$ & 0,35 \\
\hline NEK & $\% 2,5(\mathrm{n}=1)$ & $\% 9,3(\mathrm{n}=10)$ & 0,16 \\
\hline Yattığ1 gün sayısı & $29,6 \pm 15,7$ & $29,9 \pm 16,8$ & 0,91 \\
\hline
\end{tabular}


Transport edilen hastaların hipotermi, hipoglisemi ve hipoksiye maruz kalma riski çok yüksektir. Bir çalışmada transfer edilen 160 prematüre hastanın \%46'sında başvuruda hipotermi olduğunu saptamışlar (10). Başka bir çalışmada yıllar içerisinde transport edilen prematürelerde hipoterminin giderek azaldığını bildirmişlerdir (11). Çalışmamızda ise transport edilen hastaların başvuru anında \%90'nında hipotermi, $\% 2,7$ 'sinde hipoglisemi saptandı. Hastalarımızda transport mesafesi $10-350 \mathrm{~km}$ arasında idi. İki hasta hava ambulansı ile diğerleri ise kara yolu ambulansı ile sevkleri gerçekleştirildi.

RDS ve NEK prematürelerde önemli bir mortalite nedenidir. İkisinin fizyopatolojisinde hipoksinin rolü bilinmektedir. Çalışmamızda transport edilen gruptaki hastalarda RDS ve NEK sirasiyla \%65,7 ve \%9,3, transport edilmeyen grupta ise $\% 57,5$ ve $\% 2,5$ oranında görüldü $(\mathrm{p}=0,355$ ve $\mathrm{p}=0,164)$. Grup 1 'de antenatal dönemde steroid uygulama oranı \%27,7 Grup 2'de ise \%82,5 oranında idi. RDS, IVK oranının Grup 1'de düşük görülmesinde doğum öncesi steroid yapılma oranının yüksek olmasının etkisi göz ardı edilemez.

Bir çalışmada özellikle 26 haftadan küçük, ileri derecede prematürelerin doğduktan sonra sevk edilmemesi gerektiğini bildirmişlerdir (12), ancak öngörülmeyen nedenlerden dolayı uygun, boş yer olmayan ve acil nedenlerden dolayı çok kısitlı imkanların olduğu bir merkezde doğan ileri derecede prematürelerin yaşam şanslarının olması için sevk edilmesi kaçınılmazdır.

Transport edilen prematüre hastaların hastanede yatış sürelerinin daha uzun olduğu bildirilmiştir (9). Çalışmamızda iki grup arasında hastanede yatış süresi açısından anlamlı fark bulunmadı $(\mathrm{p}=0,918)$. Bu durumun, transport edilen gruptaki 5 hastanın servise yattığ 1 ilk 24 saat içinde eks olmasına bağlı olduğu düşünüldü.

\section{Sопис}

Doğduktan sonra prematürelerin transfer edilmesi mortaliteyi ve morbiditeyi arttırmaktadır. Acil durumlar dişında, en iyi transportun intrauterin transport olduğu bilinmektedir, kadın hastalıkları ve doğum uzmanlarının da bu konuda bilgilendirilmesi önemlidir. Transport şartlarının maksimum düzeyde iyileştirilmesi ile mortalite ve morbiditenin azalacağı kaçınılmazdır. Bu da yeterli ve eğitimli personel, üst düzeyde donanımlı transport araçlarının olmasını gerektirmektedir. Ya da bölgelerin doğum oranlarına göre uygun, mevcut hastanelerde yeterli donanıma sahip yenidoğan yoğun bakım servislerinin kurulmasıyla transportun minimum düzeylere düşeceği ve bunun sonucunda prematürelerin mortalite ve morbidite oranlarının gelişmiş ülkelerin düzeyine gelebileceğini düşünmekteyiz.

\section{Kaynaklar}

1. Lupton BA, Pendray MR. Regionalized neonatal emergency transport. Semin Neonatol 2004:9;125-33.

2. Field D, Draper ES. Survival and place of delivery following preterm birth: 1994-96. Arch Dis Child Fetal Neonatal Ed 1999:80;111-4.

3. Hohlagschwandtner M, Husslein P, Klebermass K, Weninger M, Nardi A, Langer M. erinatal mortality and morbidity. Comparison between maternal transport, neonatal transport and inpatient antenatal treatment. Arch Gynecology Obstet 2001:265;113-8.

4. Gülez P, Kayserili E, Sarıtaş T, Hızarcıoğlu M, Yener H, Çelik T. Yenidoğan nakilleri. ADÜ Tıp Fakültesi Dergisi 2004:5;5-10.

5. Uslu S, Aldudak B, Özdemir H. Diyarbakır'da hasta yenidoğan taşınması konusunda yapılan iyileştirme çalışmaları ve bebeklere yansımaları. Türk Pediatri Arşivi 2011;46:196-201.

6. Tarcan A, Olalı A, Tekşam M, Gürakan B. Çok düşük doğum ağırlıklı prematüre bebeklerde periventriküler-intraventriküler kanama ve periventriküler lökomalazi risk etkenlerinin incelenmesi. Türk Pediatri Arşivi 2005:40;28-32.

7. Gleissner M, Jorch G, Avenarius S. Risk factors for intraventricular hemorrhage in a birth cohort of 3721 premature infants. J of Perinatol Med 2005:28;104-10.

8. Mohamed MA, Aly H. Transport of premature infants is associated with increased risk for intraventricular haemorrhage. Arch Dis Child Fetal Neonatal Ed 2010;95:403-7.

9. Kuo S, Kimata C, Akamine K, Young B, Balaraman V. Outcomes of inborn and transported extremely premature verylow-birthweight infants in Hawai'i. Pediatr Int. 2012;54:365-9.

10. Goldsmit G, Rabasa C, Rodríguez S, Aguirre Y, Valdés M, Pretz D, et al. Risk factors associated to clinical deterioration during the transport of sick newborn infants. Arch Argent Pediatr 2012;110:304-9.

11. Bowman ED, Roy RN. Control of temperature during newborn transport: an old problem with new difficulties. J Paediatr Child Health 1997;5:398-401.

12. Holt J, Fagerli I. Air transport of the sick newborn infant: audit from a sparsely populated county in Norway. Acta Paediatr 1999;88:66-71. 